\title{
Comment on "Early introduction of complementary foods and childhood overweight in breastfed and formula-fed infants in the Netherlands: the PIAMA birth cohort study"
}

\author{
Ummu Erliana ${ }^{1}$ (D)
}

Published online: 16 May 2018

๑) Springer-Verlag GmbH Germany, part of Springer Nature 2018

\section{Dear Editor,}

Pluymen and colleagues investigated the association of early introduction of complementary foods and the risk of being overweight during childhood in formula-fed- and breastfed infants [1]. The authors used data from the Prevention and Incidence of Asthma and Mite Allergy study. However, the authors did not address asthma and allergies as confounding factors in their study. The study from Melnik [2] demonstrated that at the molecular level, allergies could accelerate the regulation of cell growth by activating amino acids through the mTORC1 signaling pathway. The mTORC1 signaling pathway in infant growth could direct to comorbidity of allergy and obesity because the alternation of a postnatal deviation from the appropriate axis of mTORC1. Furthermore, formula feeding also induced the overacting mTORC1 pathway by excessive protein intake. Therefore, infants who had allergies and were fed formula were at higher risk of becoming overweight or obese later in life.

Moreover, the authors included fruit juices and whole fruit in one group as complementary foods because they assumed that the energy content of fruit juices is similar to whole fruit. Whereas, even though fruit juices and whole fruit have the same energy content, the effect of consumption results in different responses. Children who had a high intake of juices have a higher BMI than children who have a low intake of juices [3]. Based on study by Heyman and

A Reply to this Letter to the Editor can be read here: https://doi. org/10.1007/s00394-018-1701-6.

This Letter to the Editor refers to the original publication available here: https://doi.org/10.1007/s00394-018-1639-8.

Ummu Erliana

uerliana@iu.edu

1 School of Public Health, Indiana University Bloomington, 1025 E 7th St \#111, Bloomington, IN 47405, USA
Abrams [4], juices do not contain fiber and low intake of fiber is associated with the risk of obesity [5]. In the other words, infants who consume fruit juices frequently have a higher risk of obesity than infants who consume whole fruit frequently if possible.

In conclusion, I suggest that the authors consider asthma and allergies as possible confounders and also differentiate between the results of the infants who consumed whole fruit versus fruit juices.

\section{References}

1. Pluymen LPM, Wijga AH, Gehring U, Koppelman GH, Smit HA, van Rossem L (2018) Early introduction of complementary foods and childhood overweight in breastfed and formula-fed infants in the Netherlands: the PIAMA birth cohort study. Eur J Nutr. https ://doi.org/10.1007/s00394-018-1639-8

2. Melnik CB (2014) The potential mechanistic link between allergy and obesity development and infant formula feeding. Allergy Asthma Clin Immunol J 10(37):1-10

3. Alexy U, Sichert-Hellert W, Kersting M, Manz F, Schöch G (1999) Fruit juice consumption and the prevalence of obesity and short stature in german preschool children: results of the DONALD study. J Pediatr Gastroenterol Nutr 29(3):343-349.4

4. Heyman MB, Abrams SA, Section On Gastroenterology H, Nutrition, \& Committee On, N (2017) Fruit juice in infants, children, and adolescents: current recommendations. Pediatrics. https://doi. org/10.1542/peds.2017-0967

5. Dennison BA, Rockwell HL, Baker SL (1997) Excess fruit juice consumption by preschool-aged children is associated with short stature and obesity. Pediatrics 99(1):15-22 